\title{
๑) LOCUS
}

\section{Dossiê: Patrimônio e Relações Internacionais}

https:/ / doi.org/10.34019/2594-8296.2020.v26.31068

\section{A demanda pela restituição do patrimônio cultural através das relações entre a África e a Europa}

The demand for restitution of cultural heritage through relations between Africa and Europe

La demanda de restitución del patrimonio cultural a través de las relaciones entre África y Europa

Karine Lima da Costa* bttps:/ / orcid.org/0000-0002-4815-9892

RESUMO: O presente artigo tem como objetivo analisar a questão da restituição ou repatriação dos bens culturais, especialmente os artefatos da África subsaariana, a partir da publicação do Relatório Savoy-Sarr, concluído em 2018. Analisaremos o caso dos bronzes do Benin, retirados da África no século XIX, e atualmente distribuídos em diferentes instituições museológicas, sobretudo na França e na Inglaterra. Dessa forma, ensejamos que as reflexões aqui apontadas possam inspirar outras possibilidades em relação à restituição patrimonial.

Palavras-chave: Patrimônio cultural. Repatriação. Restituição. Bronzes do Benin.

ABSTRACT: This article aims to analyze the question of the restitution or repatriation of cultural heritage, especially the artifacts from sub-saharan Africa from the publication of the Savoy-Sarr Report, completed in 2018. We'll look at the case of the Benin Bronzes, taken from Africa in the 19th century and currently distributed in different museological institutions, mainly in France and England. Thus, we hope that the reflections mentioned here may inspire other possibilities in relation to the restitution of cultural heritage.

Keywords: Cultural heritage. Repatriation. Restitution. Benin bronzes.

\footnotetext{
* Professora, Historiadora e Museóloga. Doutora em História pela Universidade Federal de Santa Catarina (UFSC). Possui interesse nas áreas de História e Museologia, com ênfase nas discussões referentes ao patrimônio, sobretudo os casos de repatriação de bens culturais. E-mail: kakalima1@gmail.com
} 
RESUMEN: Este artículo tiene como objetivo analizar la cuestión de la restitución o la repatriación de bienes culturales, especialmente artefactos del África Sub-sahariana a partir de la publicación del Informe Savoy-Sarr, completado en 2018. Veremos el caso de los Bronces de Benin, tomados de África en el siglo XIX, y actualmente distribuidos en diferentes instituciones museológicas, principalmente en Francia e Inglaterra. Por lo tanto, esperamos que las reflexiones mencionadas aquí puedan inspirar otras posibilidades en relación con la restitución de bienes patrimoniales.

Palabras clave: Patrimonio cultural. Repatriación. Restitución. Bronces de Benin.

\section{Como citar este artigo:}

Costa, Karine Lima da. "A demanda pela restituição do patrimônio cultural através das relações entre a África e a Europa”. Locus: Revista de História, 26, n.2 (2020): 193-209.

\section{Introdução}

A noção moderna do conceito de patrimônio no Ocidente se consolidou a partir do final do século XVIII, e da constituição dos estados nacionais modernos (Lowenthal 1998), contudo, sabe-se que a sua acepção é mais antiga e pode ser encontrada mesmo em sociedades tribais (Gonçalves 2007). Entretanto, a categoria de patrimônio ainda é pensada sob perspectiva individualizada que a aproxima da ideia de propriedade, o que não é incomum, já que o conceito de patrimônio nos remete à noção romana de pater familias, ou seja, “[...] um conjunto de bens (herança), que devem ser mantidos na família e transmitidos às futuras gerações” (Costa 2018, 101). Esse sentido de herança promove uma série de rivalidades e disputas, das quais o patrimônio cultural não está alheio:

Enquanto o patrimônio cultural incorpora valores diferentes e pode ser instrumentalizado para servir distintos objetivos econômicos, sociais e políticos dentro de contextos de desenvolvimento, o passado se torna moeda de troca cultural no momento em que se coloca como imprescindível à vivência humana: há aqui um nexo causal interessante a ser analisado. A herança de povos e seu passado: balizas para a compreensão do presente (Christofoletti 2017, 5).

Exemplo dessas disputas são encontradas nas instituições museológicas, concebidas através da junção entre o poder e a memória, uma vez que a etimologia da palavra se refere ao antigo templo dedicado às nove musas filhas de Zeus, o deus da autoridade e do poder e de Mnemosine, a deusa da memória. Assim, na análise da emergência dos museus distinguimos o enfoque de cada instituição na exaltação do poder da memória ou no apelo à memória do poder: "reconhecer que existem relações entre o poder e a memória implica em politizar as lembranças e os esquecimentos" (Chagas 2009, 44). 
Assim como o patrimônio ocidental, a África também possui uma herança cultural viva e diversificada, seja ela material ou imaterial, embora o seu patrimônio tangível e intangível seja, muitas vezes, indissociável (Keitumetse 2016). Essa multiplicidade pode ser encontrada nas artes, nas crenças e nos ofícios que advêm dos seus antepassados e que ainda são recorrentes em alguns modos de fazer e viver. Contudo, para além dessa riqueza material, os países africanos possuem uma tradição histórica muito mais antiga que os países europeus, o que levou aos saques e pilhagens cometidos, sobretudo, durante o período colonial.

Naquele momento, o exercício do poder de uma nação sobre outra (ou sobre outras) se desenvolveu, também, por meio do domínio científico e cultural, no qual a diplomacia teve um papel essencial. A apropriação, transferência e posterior exposição de documentos, objetos, monumentos e até restos mortais são exemplos desse tipo de dominação, como a difusão das feiras e exposições universais no decorrer do século XIX.

Através dos olhares estrangeiros, o mundo era representado enquanto um objeto nessas exposições, assim como os chamados objetos etnográficos eram exibidos nos nascentes museus ocidentais para ilustrar “[...] as etapas da evolução sociocultural e os trajetos de difusão cultural" (Gonçalves 2007, 16). Ao identificar a forma e a composição material de cada objeto produzido, poderia se constatar as técnicas empregadas e o grau de conhecimento dos diferentes grupos sociais.

Segundo as reflexões do filósofo alemão Walter Benjamin (1987), o passado não é algo inerte que ocorreu há muito tempo e que não pode mais ser invocado ou mesmo modificado, pelo contrário, ele demonstrou que podemos recorrer a este mesmo passado para a construção de novas perspectivas acerca do presente, visando a sua transformação. Nesse sentido, notabilizamos a importância da crítica pós-colonial (ou decolonial) de desconstrução de narrativas que foram naturalizadas ao longo do tempo, pois ela nos auxilia a repensar a forma como esse passado foi tratado e apresentado.

Os princípios teóricos da crítica pós-colonial desenvolveram-se por meio dos estudos culturais e literários no decorrer da década de 1960, e posteriormente foram propagados em outras áreas do conhecimento, como a História, a Antropologia, a Filosofia, entre outras. Trazendo à luz outras concepções e narrativas possíveis, essa perspectiva “[...] resiste à busca de formas holísticas de explicação social. Ela força um reconhecimento das fronteiras culturais e políticas mais complexas que existem no vértice dessas esferas políticas frequentemente opostas" (Bhabha 1998, 241-242). Na esperança de suplantar formas hegemônicas de análise e representação de outros 
povos, seus críticos buscaram interpretar os seus próprios processos históricos, nos quais a relação com o patrimônio cultural também foi contemplada:

Privadas do patrimônio material pelas pilhagens e compras imperiais e pós-imperiais, as culturas não-ocidentais que internalizaram os valores ocidentais também se privaram de modos alternativos de interpretar seu passado particular (Lowenthal 2004, 302, tradução nossa).

Foi essa conjuntura que possibilitou a algumas comunidades a reivindicação pelo retorno de exemplares do patrimônio cultural oriundos de vários territórios e que atualmente encontramse fora dessas localidades, especialmente sob a guarda de instituições culturais e museológicas. São objetos, monumentos, obras de arte e até remanescentes humanos que foram levados em diferentes circunstâncias. Nos últimos anos observamos o crescimento da discussão em torno dessas requisições, o que deu lugar ao movimento internacional em torno da repatriação de bens culturais.

Juridicamente, a devolução desses bens pode ser interpelada por meios das noções de retorno, restituição ou repatriação (Kowalski 2005), termos que variam conforme cada autor alguns são utilizados, muitas vezes, como sinônimos. O retorno está ligado aos objetos que foram deslocados de seus territórios originais durante o período colonial ou quando foram exportados ilegalmente (Cornu e Renold 2010). Restituição também se refere a um cenário de desapropriação ilegal e se adequa à devolução de objetos saqueados ou pilhados, principalmente durante os períodos de guerra e ocupação: “a restituição é unilateral (com base em leis ou decisões administrativas) ou bilateral (negociada com ou sem mediação ou referida a arbitragem)" (Cornu e Renold 2010, 10, tradução nossa). A diferença é que a restituição prevê um destinatário que pode ser identificado e o retorno presume um território.

A repatriação pode ser vista como uma forma de restituição, seja para um país ou para uma comunidade solicitante (Cornu e Renold 2010) ou mais claramente como o retorno de algo que está fora do seu país de origem, embora para alguns também possa se tratar de retornos entre instituições do mesmo país (Prott 2009).

A questão da repatriação é bastante complexa. No entanto, a sua resolução não se restringe apenas ao âmbito jurídico. Em algumas situações, o processo como um todo é mediado por órgãos como a Organização das Nações Unidas para a Educação, a Ciência e a Cultura (UNESCO) e o Conselho Internacional de Museus (ICOM), organizações fundamentais no fomento desse tipo de diálogo. Criada após a Segunda Guerra Mundial para assegurar a cooperação entre diferentes países, a Unesco atua por meio de cinco programas específicos: Educação, Ciências Naturais, Ciências Humanas e Sociais, Cultura e Comunicação e Informação'

\footnotetext{
${ }^{1}$ Disponível em: https://nacoesunidas.org/agencia/unesco/ Acesso em: 09 abr. 2020.
} 
É importante destacar que a UNESCO trabalha em harmonia com a dinâmica dos acontecimentos internacionais e, por isso, prioriza a inserção de temas contemporâneos na construção de suas agendas, buscando contribuir para a cooperação entre os povos e a promoção da paz. Além disso, está inserida no âmbito das organizações internacionais de caráter global, tendo se constituído a partir do interesse manifesto e formalizado - por meio de um tratado internacional - por seus Estados partes (Christofoletti 2017, 3).

Durante a Conferência Geral da UNESCO em novembro de 1970, a discussão em torno da restituição dos bens culturais teve um avanço significativo com a adoção da Convenção sobre os Meios de Proibição e Prevenção à Importação, Exportação e Transferência Ilícita de Propriedade de Bens Culturais, que em 2020 completou cinquenta anos. Mesmo que a vigência da convenção tenha sido iniciada em 1972 e não seja retroativa, essa questão ascendeu o debate à comunidade internacional, assim como a demora por parte de alguns países para ratificá-la, como foi o caso da França (1997), do Reino Unido (2002), da Alemanha (2007) e da Bélgica (2009)².

Seis anos depois a questão da apropriação ilícita dos bens culturais foi discutida por especialistas em Veneza, devido à falta de procedimentos internacionais específicos para lidar com esse tipo de demanda. Dessa forma, em 1978 foi criado oficialmente o Comitê Intergovernamental para a Promoção do Retorno de Bens Culturais aos seus Países de Origem ou sua Restituição em Caso de Apropriação Ilícita (ICPRCP), de natureza consultiva (e permanente) para mediar as negociações bilaterais e multilaterais entre os seus Estados-Membros. Os casos que podem ser analisados pelo comitê incluem apropriações realizadas durante o período colonial ou durante períodos de ocupação e também o tráfico ilícito de bens culturais ${ }^{3}$.

A atuação do comitê viabilizou o retorno de mais de doze mil artefatos pré-colombianos ao Equador em 1983, após sete anos de discussões; a devolução da Alemanha para a Turquia de sete mil tabletes cuneiformes em 1987; uma máscara de Makondé que foi devolvida à Tanzânia pelo Museu Barbier-Mueller, em Genebra, em 2010, após quatro anos de negociações; entre outros casos $^{4}$.

O Comitê Intergovernamental só atua após tentativas frustradas de negociação entre os interessados e os pedidos precisam ser encaminhados através de um documento específico Formulário padrão relativo a pedidos de devolução ou restituição ${ }^{5}$ - com um prazo mínimo de seis meses antes da próxima sessão ordinária que ocorre a cada dois anos. Os campos especificados no

\footnotetext{
2 “França vai devolver 26 obras de arte ao Benin”. DW Brasil, 24/11/2018. Disponível em: https://www.dw.com/ptbr/fran\%C3\%A7a-vai-devolver-26-obras-de-arte-ao-benin/a-46433723 Acesso em: 20 jun. 2020.

${ }^{3}$ Informações disponíveis no site oficial da UNESCO: http://www.unesco.org/new/en/culture/themes/restitutionof-cultural-property/intergovernmental-committee/historical-background/Acesso em: 20 jun. 2020.

4 Disponível em: http://www.unesco.org/new/fr/culture/themes/restitution-of-cultural-property/committessuccessful-restitutions/ Acesso em: 20 jun. 2020.

${ }^{5} \mathrm{O}$ formulário foi elaborado pelo Comitê em janeiro de 1981 e deve ser preenchido por ambas as partes interessadas.
} 
documento contemplam a descrição do objeto; o local onde se encontra atualmente; o país solicitante; o status legal; o estado de conservação; referências e documentação; informações sobre a forma e o período em que o objeto deixou o local de origem; e um histórico das tentativas de negociações anteriores. O comitê especifica que apenas um objeto deve ser solicitado por vez em cada formulário e caso se trate de uma coleção, a mesma deverá ser tratada como "uma entidade".

\section{Ascensão do debate na Europa}

No final de janeiro de 2020, foi aprovada em Portugal a proposta de lei $\mathrm{n}^{\circ}$ 5/XIV/1 sobre o aditamento do orçamento do Estado, pela então deputada do partido Livre, Joacine Katar Moreira ${ }^{6}$. Nela, o Artigo 203 - A propôs um "Programa para a Descolonização da Cultura" através da destinação de verbas do Governo para a Direção Geral do Patrimônio Cultural (DGPC). Estas verbas deveriam ser utilizadas para a organização de uma comissão muldisciplinar que definirá as diretrizes "[...] para a recontextualização das coleções dos museus e monumentos nacionais" (Moreira 2020, 2). A ideia de recontextualização deve-se às novas narrativas de descolonização política, institucional e dos saberes, que agora visam “[...] a descolonização do conhecimento e da cultura para uma efetiva descolonização das sociedades ocidentais" (Moreira 2020, 1). Como sugestão, o documento citou instituições portuguesas como o Museu Nacional de Arte Antiga, o Museu Nacional de Etnologia, o Museu Nacional de Arqueologia, a Torre de Belém e o Mosteiro dos Jerônimos, com ênfase na reestruturação das narrativas sobre o passado escravagista colonial.

Além dessas diretrizes, a proposta prevê uma listagem de todas as obras e os monumentos que atualmente se encontram em instituições arquivísticas e museológicas portuguesas e que foram retiradas de suas antigas colônias. Esse inventário não representa obrigatoriamente a devolução dos bens culturais, mas objetiva facilitar a identificação e posterior reclamação por parte dos países interessados.

Joacine Moreira é de origem guineense, formada em História e com doutorado em Estudos Sociais. Dentre as causas defendidas pela deputada encontram-se a luta pelo meio ambiente e o combate ao preconceito racial. Ela afirma que as questões de restituição dos bens culturais precisam avançar para a sua institucionalização, já que ainda há muita resistência nesse ponto: “[...] estas propostas têm como objetivo institucionalizar, nacionalizar e politizar a discussão sobre a

\footnotetext{
${ }^{6}$ Desde o início de fevereiro de 2020, sua situação no partido é de deputada não-inscrita, ou seja, ela não faz mais parte do parlamento, pois a sua confiança foi retirada após uma série de divergências com o partido. Disponível em: https:/ / expresso.pt/politica/2020-01-31-Livre-retira-a-confianca-politica-a-Joacine-Katar-Moreira.-Hoje-nao-e-umdia-feliz-para-o-partido Acesso em: 09 abr. 2020.
} 
descolonização do conhecimento, da cultura, do imaginário, e assim sucessivamente" (Moreira 2020). Embora a sua proposta pareça um pouco ambiciosa, ela defende que o ato de restituição em si não é o objetivo principal de sua iniciativa, mas uma ampliação dessa discussão no âmbito do patrimônio nacional português, no intuito de pensar outras formas de olhar para esse patrimônio considerado, também, fruto da violência e do espólio perpetrados pelo colonialismo português ${ }^{7}$.

As ideias defendidas pela deputada Jociane Moreira certamente tiveram influência após as declarações do presidente francês Emmanuel Macron sobre a devolução de obras de arte e objetos africanos que atualmente se encontram na França. Durante um longo discurso proferido na Universidade de Ouagadougou, em Burkina Faso, no final de novembro de 2017, o presidente alegou que não poderia “[...] aceitar que grande parte do patrimônio cultural de vários países africanos esteja na França" ${ }^{8}$ ". O discurso voltado "À L'Afrique" inaugurou a viagem de Macron pelo continente africano, com o objetivo de reforçar as relações diplomáticas entre o continente e a França e tocou em pontos essenciais como cultura, educação, política, economia, segurança, entre outros.

Macron utilizou pontos chaves em sua retórica para se aproximar dos seus ouvintes, especialmente ao enfatizar o reconhecimento da multiplicidade e da diversidade do continente africano. Ele afirmou que a sua geração não conhece a África "[...] como um continente colonizado", mas que lembra, sobretudo, das realizações de Nelson Mandela e da solidariedade pan-africana:

Não estarei do lado daqueles que veem na África o continente de crises e miséria, mas não estarei do lado daqueles que exaltam uma África encantada, uma África subitamente adornada com todas as virtudes e erguida como modelo. (...) Estarei do lado daqueles que têm um olhar lúcido. Aqueles que consideram que a África não é um continente perdido nem um continente salvo. Considero que a África é simplesmente o continente central, global, essencial porque é aqui que todos os desafios contemporâneos colidem? .

No âmbito educacional, Macron destacou a importância do acesso de estudantes e pesquisadores africanos aos mesmos manuais e conteúdos disponíveis aos franceses, bem como a recepção de "novos talentos" com oportunidades de estudos e trabalho em diversas áreas na França e vice-versa. Ao se encaminhar para o final do discurso, o presidente manifestou a vontade de restituir - temporária ou permanentemente - os bens culturais africanos presentes em museus e

\footnotetext{
${ }^{7}$ Entrevista de Joacine Moreira à DW, publicada em 04 de fevereiro de 2020. Disponível em: https://www.dw.com/pt002/deputada-joacine-katar-moreira-n $\%$ C3\%A3o-desiste-da-descoloniza $\% \mathrm{C} 3 \% \mathrm{~A} 7 \% \mathrm{C} 3 \% \mathrm{~A} 3 \mathrm{O}$-do-conhecimento/a52250095 Acesso em: 09 abr. 2020.

$8 \mathrm{O}$ discurso na íntegra do presidente francês pode ser consultado no site do Jeune Afrique. Disponível em: https://www.jeuneafrique.com/497596/politique/document-le-discours-demmanuel-macron-a-ougadougou/

Acesso em: 10 abr. 2020.

${ }^{9}$ Idem.
} 
coleções europeias, em até cinco anos: "o patrimônio africano deve ser destacado em Paris, mas também em Dakar, Lagos, Cotonou, esta será uma das minhas prioridades" (Macron 2017, tradução nossa).

Para a realização desse ensejo, Macron definiu a criação de parcerias que envolvam diferentes profissionais entre curadores, historiadores e museólogos, a fim de coibir o tráfico ilícito de objetos e obras de arte, facilitado tanto pelos europeus quanto pelos africanos. Isso envolve também a segurança dessas obras e a ampliação das temáticas africanas que são exibidas nos museus europeus, pois estes geralmente apresentam e exaltam a história antiga da África, mas abrem pouco espaço para a sua história contemporânea.

Essa etapa foi cumprida através de um relatório encomendado por Macron à historiadora da arte francesa, Bénédicte Savoy, e ao economista senegalês, Felwine Sarr. O documento intitulado "La restitution du patrimoine culturel africain. Vers une nouvelle étbique relationnelle" (A restituição do patrimônio cultural africano. Rumo a uma nova ética relacional) foi entregue em novembro de 2018, e recomendou a restituição permanente de cerca de noventa mil artefatos da África subsaariana, a maioria hospedada no Museu do Quai Branly-Jacques Chirac, em Paris, especializado em culturas antigas não europeias.

O relatório Savoy-Sarr prevê que os processos de restituição passem por três fases, no qual a primeira (de novembro de 2018 a 2019), contemplou a entrega do documento e uma lista dos possíveis países que poderiam se interessar pelo retorno, como Benin, Senegal, Nigéria, Etiópia, Mali e Camarões, além do apontamento de alguns artefatos específicos.

A segunda fase, prevista para ocorrer entre a primavera de 2019 e novembro de 2022, recomenda a realização de inventários dos museus públicos franceses sobre as obras de arte africanas e o compartilhamento digital dessas informações através de um banco de dados acessíveis a todos. Também sugere a realização de oficinas e a criação de comissões compostas por representantes franceses e africanos de cada país interessado na restituição dos bens culturais para discutir os procedimentos a serem seguidos. A terceira fase deverá abarcar os retornos e está prevista para iniciar em novembro de 2022, sem data para a sua finalização.

Segundo o relatório, a restituição reconhece a propriedade ilegal do objeto em questão, independentemente do tempo que tenha se passado:

Falar abertamente de restituições é falar de justiça, ou um reequilíbrio, reconhecimento, de restauração e reparação, mas acima de tudo: é uma maneira de abrir um caminho para o estabelecimento de novas relações culturais com base em uma relação ética recentemente refletida (Sarr e Savoy 2018, 29, tradução nossa). 
O posicionamento do presidente francês e a iniciativa do relatório foram pontos extremamente positivos para a continuidade dessa discussão, especialmente porque contempla as obras e os objetos que deixaram os seus países durante o período colonial, no qual existe uma lacuna na documentação comprobatória que assegura a legalidade ou ilegalidade do trânsito desses bens. O caminho a percorrer até a efetivação das restituições é longo e a dificuldade em efetivar essas ações esbarra, principalmente, nas questões legais, sejam elas nacionais ou internacionais. No caso francês existe uma legislação que torna as suas coleções públicas imprescritíveis e inalienáveis (Savoy e Sarr 2018). Embora essa lei tenha sido anulada durante a Revolução Francesa e ainda seja contestada por algumas pessoas, ela retornou no decorrer do século XIX, e é utilizada como principal alegação para a negativa francesa em torno das restituições, como ocorreu no caso da devolução dos bronzes do Benin, um ano antes da proposta de Macron.

O caso desses artefatos encontra-se no centro do debate. Trata-se de um conjunto de esculturas que foram encomendadas pela realeza e retratavam a história do antigo Reino do Edo, nome local do grupo que, no Ocidente, se convencionou chamar de Benin: "desde os primeiros contatos entre o Edo e os portugueses no final do século XV, o Edo é geralmente referido no Ocidente com os nomes 'Bini' ou 'Benin”' (Lundén 2016, 2, tradução nossa). Essa região corresponde à localidade atual ao sul da Nigéria.

Em 1897, a capital do Reino foi ocupada pelas tropas militares britânicas e integrada à colônia britânica da Nigéria, momento em que muitos artefatos foram tomados como despojos de guerra e retirados da África. Posteriormente, vários museus adquiriram itens dessa vasta coleção, ficando o Museu Britânico com a maior parte, composta por cerca de setecentos objetos (Lundén 2016), mas a instituição contabiliza novecentos objetos. Dentre eles, destacamos a cabeça da rainha-mãe Idia, objeto que juntamente com a Pedra de Rosetta e os mármores do Parthenon representam símbolos de culturas de grande importância para o acervo do museu - e que também estão entre os pedidos oficiais de devolução feitos pelo Egito e pela Grécia, respectivamente.

Ao total, estima-se que a coleção do Benin seja formada por mais de mil peças esculpidas em bronze, madeira e marfim. Atualmente esses objetos encontram-se divididos entre dez instituições museológicas ocidentais na Alemanha, na Holanda, na Inglaterra e nos Estados Unidos. $\mathrm{Na}$ África, alguns museus nigerianos abrigam parte da coleção, na qual muitas peças foram adquiridas através de transações comerciais entre o Museu Britânico e o governo nigeriano, na década de 1950.

Por sua beleza e técnica, essas esculturas ficaram mundialmente conhecidas como exemplares únicos da arte do Benin. No entanto, para o povo Edo as peças possuíam significado 
espiritual: cumpriam funções ritualísticas e ornamentavam altares ancestrais no interior do palácio do oba (rei) e nas residências de pessoas mais abastadas (Lundén 2016).

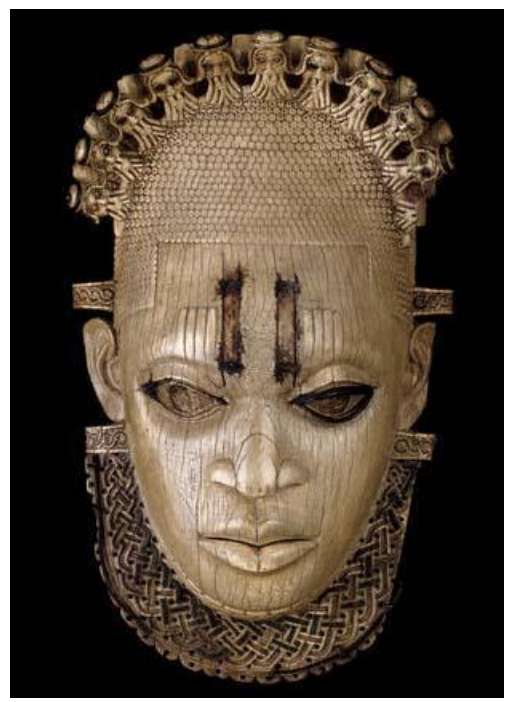

Fig. 1: Coleção do Museu Britânico, "Representação da Rainha-mãe Idia”, https://www.pambazuka.org/democracy-governance/european-museums- $\%$ E2\%80\%981oan $\%$ E2\%80\%99-lootedbenin-bronzes-nigeria. Acesso em: 08 ago. 2020.

O objeto acima é um dos mais significativos do acervo, tanto para o Museu Britânico quanto para os nigerianos. A máscara de marfim da rainha Idia chegou a ser solicitada na década de 1970, para a celebração de um festival africano (FESTAC - Festival Mundial de Artes e Cultura Negras e Africanas), mas o pedido de empréstimo foi negado. Segundo o Museu Britânico, o objeto é muito frágil para viajar, embora afirme que muitas peças são regularmente emprestadas para instituições estrangeiras ${ }^{10}$. Dessa forma, escultores locais confeccionaram uma réplica da máscara para o festival, já que a sua imagem havia se tornado uma espécie de "símbolo" do evento".

As sucessivas negativas de empréstimo e/ou devolução de determinados artefatos por parte do Museu Britânico podem ser encontradas na própria página oficial do museu na Internet, com alegações de que a instituição adquiriu legalmente esses objetos e que a sua exibição para milhares de pessoas é concedida de maneira livre e gratuita. Sobre a forma de aquisição dos artefatos, a instituição justifica a dominação do comércio na costa nigeriana durante o século XIX, e reconhece a violência, os saques e a espoliação contra o Reino do Edo ${ }^{12}$ : "a narrativa imperial interfere na

10 Disponível na página do Museu Britânico: https://www.britishmuseum.org/about-us/british-museumstory/objects-news/benin-bronzes Acesso em: 09 ago. 2020.

${ }^{11}$ Informações disponíveis em: https://www.redbull.com/br-pt/dudus-playlist-festac-77 Acesso em: 09 ago. 2020.

$12 \mathrm{O}$ museu afirma que embora sejam dadas inúmeras declarações públicas por parte dos africanos, nunca recebeu um pedido formal por escrito para a devolução da coleção do Benin. Disponível em: https://www.britishmuseum.org/about-us/british-museum-story/objects-news/benin-bronzes Acesso em: 09 ago. 2020. 
narrativa cultural do Benin e, em um nível macro, com o desenvolvimento da narrativa pósindependência da Nigéria" (Kiwara-Wilson 2013, p. 394, tradução nossa).

A instituição inglesa não é a única que se vale do discurso de gratuidade e de amplo acesso ao conhecimento de diferentes culturas. Em 2004, a revista ICOM News publicou um documento intitulado "Declaração da Importância e Valor dos Museus Universais" (DIVUM), assinada por diretores de dezenove instituições europeias e norte-americanas. O documento assinala a importância da "universalidade" encontrada nesses museus e se opõe à devolução das coleções, uma vez que a sua aquisição ocorreu em tempos e condições diferentes das atuais (ICOM 2004). Obviamente, essas e outras alegações contidas no documento são contestadas por muitos intelectuais africanos, como o arqueólogo queniano George Abungu, que questiona a ideia de centralidade da universalidade, afirmando que todo museu "[...] deve ter algo especial que o torne de valor universal para a humanidade" (Abungu 2004, 5, tradução nossa).

Em 2010, foi criado o grupo de trabalho "The Benin Dialogue Group”, com representantes da Nigéria e de alguns museus europeus para reforçar ações colaborativas que viabilizem o empréstimo e a rotação de obras de arte, além da criação do Museu Real de Benin, previsto para ser inaugurado em 2021. A ideia é que cerca de trezentos itens estejam presentes na exposição de longa duração do museu.

Em 2018, o grupo firmou um acordo com o Museu Britânico para o empréstimo de alguns desses objetos para uma exposição temporária no novo museu nigeriano, o que gerou uma insatisfação por parte de alguns africanos: "desde quando saqueadores ou seus sucessores emprestam os objetos roubados aos donos em vez de devolvê-los de maneira simples e correta?” (Opuku-Agyemang 2017). Kwame Opoku-Agyemang também fez duras críticas à DIVUM, considerando-a um "projeto arrogante imperialista", que não abre mão dos erros cometidos durante o período colonial (Opuku-Agyemang 2013). Na sua percepção, o empréstimo dos artefatos pode indicar um avanço, mas também um grande retrocesso: “devemos estar cientes de que, ao aceitar um empréstimo de artefatos saqueados do Benin, pode-se considerar que alguém reconheceu a propriedade ou os direitos de propriedade dos museus sobre os artefatos" (OpokuAgyemang 2017).

Embora alguns desses museus ocidentais apelem para a questão da difusão do conhecimento através da exposição de suas coleções, eles ignoram o fato de que o patrimônio africano ainda está vivo e presente na transmissão de tradições entre os descendentes e os seus antepassados: 
A África precisa não apenas de desculpas e perdão, mas que esses tesouros culturais africanos inestimáveis - obras de arte, ícones, relíquias - sejam devolvidos aos seus legítimos proprietários. [...]. Essas obras são parte integrante da definição de nossa identidade e personalidade como família, como família africana. Nós conversamos com eles. Eles falam conosco. Nós os tocamos em certos momentos de nossas vidas, desde o nascimento, passando pela vida até a morte. É por meio deles que os espíritos vivos de nosso povo, de nossa história, de nossa cultura interagem e fazem interface conosco. Eles não estão lá, daí o vazio em nossas mentes e em nossos corações. Continuamos a chorar para que eles voltem para casa, para completar esse espaço cultural e espiritual (Gurirab apud Kiwara-Wilson 2013, 1, tradução nossa).

Os museus não são os únicos detentores atuais de obras de arte e objetos capturados durante o período colonial. Em 2015, uma iniciativa do neto de um capitão britânico repatriou à Nigéria dois bronzes que foram obtidos pelo seu avô durante a ocupação britânica do Benin, no século XIX. Quando os herdou, em 2013, Mark Walker optou pela repatriação, já que não desejaria que os objetos fossem vendidos em um leilão após a sua morte e os seus filhos não demonstraram interesse em mantê-los na família. Após entrar em contato com a Sociedade Richard Lander, Walker viajou até a Nigéria em 2014, e os entregou ao bisneto do rei deposto pelo seu avô na época da invasão ${ }^{13}$ - uma atitude incomum por parte dos detentores de tais artefatos e que foi bastante comemorada pelos nigerianos. O diário do seu avô também foi doado e nele contém imagens e textos que narram a violenta investida dos britânicos no antigo Reino do Benin, bem como os saques por eles empreendidos.

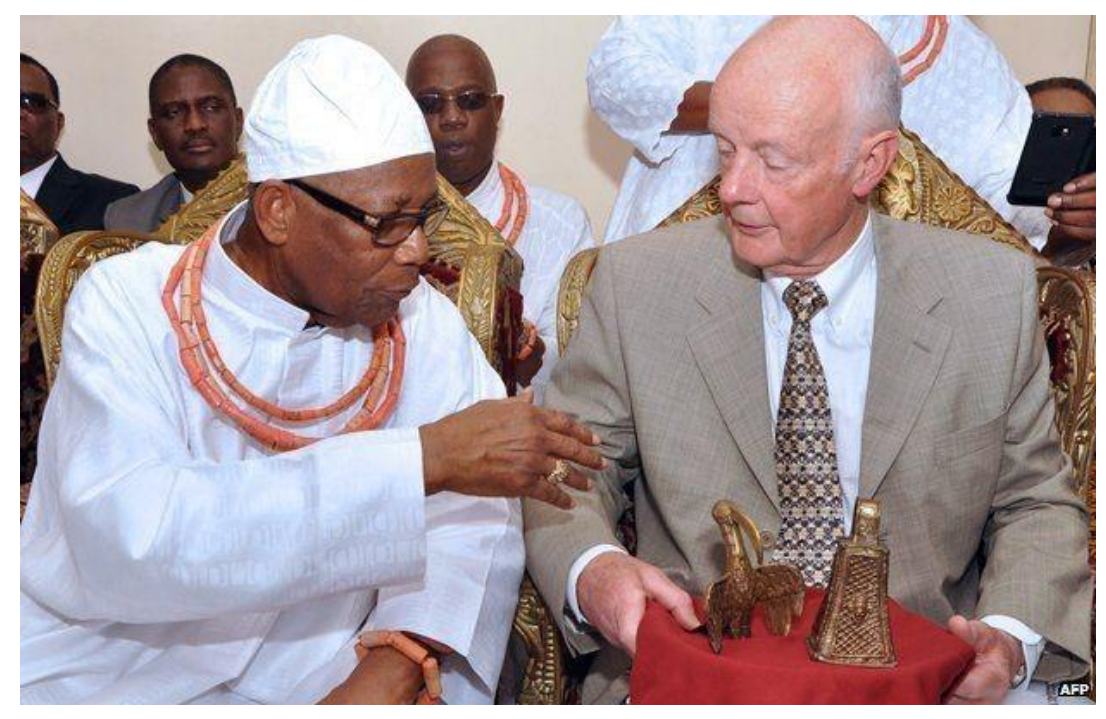

Fig. 2: "Cerimônia de entrega dos objetos de Mark Walker ao príncipe Edun Akenzua", https://www.bbc.com/news/magazine-31605284. Acesso em: 03 mai. 2020.

Esse retorno e a sinalização de outras restituições é motivo de orgulho para muitos descendentes dos antigos artesãos que atualmente vivem na mesma região, como Eric Ogbemudia:

\footnotetext{
${ }^{13}$ Disponível em: https://www.bbc.com/news/magazine-31605284 Acesso em: 03 mai. 2020.
} 
“eu nunca vi essas peças ao vivo, nunca lhes toquei nem as senti. Só as vimos em catálogos. É muito revoltante e muito triste" ${ }^{\prime 14}$. Ele segue a tradição e ainda produz peças em bronze na sua oficina situada na rua Igun, um dos locais onde eram confeccionadas as peças no século XIII, considerada Patrimônio Mundial da UNESCO.

Recentemente o governo francês anunciou que devolverá ao Benin vinte e seis objetos que foram tomados pelo exército francês na década de 1890, a primeira restituição anunciada após a publicação e divulgação do relatório Savoy-Sarr.

Além das questões éticas e legais que envolvem essas solicitações, existem ainda as implicações simbólicas, filosóficas e relacionais, pois “[...] as restituições abrem uma profunda reflexão sobre a história, as memórias e o passado colonial" (Savoy e Sarr 2018, 29, tradução nossa). Dessa forma, mesmo que muitas das requisições não venham a ser atendidas, elas nos convocam à reflexão acerca do passado e de histórias sensíveis que ainda não foram superadas.

Muitos escritores africanos criticam a disparidade entre a importância que os europeus dispensam aos objetos da cultura africana e o tratamento em relação aos indivíduos, principalmente aos migrantes africanos:

O paradoxo imediato aqui é que, enquanto objetos da periferia eram bem-vindos no centro, as pessoas não eram. Desde a independência dos países da África Ocidental no final dos anos 1950 e início dos anos 60 , a retenção de objetos e a rejeição simultânea de pessoas tornaram-se cada vez mais preocupantes. Jovens migrantes sem documentos de antigas colônias francesas ficam a alguns metros do Museu do Quai Branly - Jacques Chirac, um museu em Paris cheio de seu patrimônio inacessível. Os migrantes são tratados com desprezo enquanto os objetos de suas pátrias são cuidados em museus e tratados com grande reverência. Os migrantes serão deportados, mas os objetos não serão repatriados. A terra natal é, portanto, apenas o lar de objetos, não de pessoas (Joy 2019, s.p., tradução nossa).

Outra crítica dirigida aos museus europeus que detém uma grande quantidade de objetos oriundos de outros países é a real importância que esses artefatos adquirem nessas instituições. Até que ponto eles são valorizados porque representam uma cultura diferente e não porque exaltam a própria história nacional (repleta de conflitos e lutas desiguais)? Se os objetos africanos são tão importantes para a Inglaterra ou para França, o que sobra para os países africanos? (Costa 2019).

\section{Considerações finais}

Discutir as circunstâncias da retirada desses objetos e obras de arte de suas terras natais nos séculos anteriores nos auxilia na percepção da manutenção de discursos que ainda permanecem

\footnotetext{
${ }^{14}$ Reportagem intitulada "Europa vai devolver à Nigéria obras de arte da época colonial", publicada pelo DW em 14 de novembro de 2018. Disponível em: https://www.dw.com/pt-002/europa-vai-devolver-0C3\%A0nig\%C3\%A9ria-obras-de-arte-da-\%C3\%A9poca-colonial/a-46296306 Acesso em: 09 abr. 2020.
} 
estabelecidos nos grandes museus classificados como "enciclopédicos", ou seja, aqueles que se dedicam à representação de culturas distintas. Afinal, será que os visitantes do Museu Britânico têm acesso às informações contidas no diário do antigo soldado britânico ao realizarem a sua visita pela seção de Arte africana? E na exposição dos mármores do Parthenon, será que encontramos alguma legenda referente aos debates sobre os pedidos de repatriação por parte da Grécia? A sala que abriga a Pedra de Rosetta faz alguma menção à remoção de monumentos e objetos durante a invasão de Napoleão Bonaparte ao Egito? Será que a incursão do exército francês no norte da África é entendida como uma invasão ou considerada apenas uma "expedição"? Essas e outras informações são extremamente relevantes e precisam estar presentes no discurso expográfico do museu: "ao evitar exibir o eu ocidental, ela se enquadra na tradição dominante de exposições em museus que habitualmente se abstém de exibir o eu branco masculino ocidental nos mesmos termos que exibe seus vários outros" (Lundén 2016, 443, tradução nossa).

Esses questionamentos são indispensáveis na discussão sobre a repatriação ou restituição dos bens culturais. Contudo, as reivindicações devem ser olhadas à luz do presente e das concepções do mundo contemporâneo: quem está fazendo essas solicitações? Quais as justificativas? De que forma o processo de repatriação será realizado? Onde esses objetos serão alocados? Quais as medidas que garantirão a sua conservação? Os objetos deveriam mesmo estar expostos para o mundo todo? Se essas dúvidas não forem exaustivamente debatidas entre os interessados, não se chegará a uma resolução coerente para os africanos: “até que o povo de Benin recupere o controle do passado, as informações que acompanham os objetos expostos e a caracterização de sua importância serão sempre favoráveis ao passado imperial” (Kiwara-Wilson 2013, p. 396, tradução nossa).

No final de janeiro de 2020, a Grã-Bretanha atestou a sua saída da União Europeia (UE), após ingressar em 1973, episódio que ficou conhecido como Brexit ${ }^{15}$. Essa ação foi precursora, já que foi a primeira vez que um país deixou a UE. Em fevereiro de 2020, a UE decidiu incluir nas negociações uma cláusula sobre a reavaliação da conduta britânica em relação à devolução de bens culturais que foram retirados de seus locais de origem ilegalmente e hoje estão sendo reclamados.

Essa ressalva reacendeu um debate que se estende publicamente desde a década de 1980, quando a então Ministra da Cultura da Grécia, Melina Mercouri, entrou com um pedido oficial de devolução das esculturas que compõem os Mármores do Parthenon, retirados de Atenas e

\footnotetext{
15 Abreviação para "British exit", traduzido como "saída britânica", que se oficializará em 31 de dezembro de 2020. Informações disponíveis em: https://www.bbc.com/portuguese/internacional-46335938 Acesso em: 21 abr. 2020.
} 
adquiridos pelo Museu Britânico no início do século XIX ${ }^{16}$. Obviamente os britânicos não concordaram com essa ideia e reafirmaram que os mármores pertencem legalmente ao museu, como já relatado.

Embora muitos acreditem que a nova cláusula do documento se refere à antiga contenda entre os britânicos e os gregos - inclusive porque a sua proposta de inclusão partiu da Grécia, em conjunto com o Chipre, a Espanha e a Itália -, outros defendem que essa preocupação é condizente com a postura adotada pela UE em relação aos danos causados pelo tráfico ilícito ou mesmo a destruição do patrimônio cultural, independentemente do país ${ }^{17}$.

Fala-se muito nos casos que não foram (e talvez nunca serão) solucionados, mas através dos exemplos que já foram resolvidos percebemos que o diálogo e a cooperação entre os responsáveis pela salvaguarda do patrimônio cultural são os meios mais profícuos para um desfecho final nas reivindicações sobre os bens culturais.

Obviamente o retorno das antiguidades dispersas não representa um fim, mas como expresso por Savoy e Sarr (2018), falar sobre restituição de obras de arte significa abrir caminho para um novo capítulo na história, para que ela possa ser reescrita de outra forma, com novos personagens e novas roupagens, como ocorreu com os Maori da Nova Zelândia que optaram por deixar alguns de seus artefatos no exterior com vistas a "[...] aumentar a conscientização internacional da identidade maori” (Lowenthal, 2004, 309, tradução nossa).

São novas formas de se relacionar com o patrimônio cultural que a problemática da repatriação convoca, pois ao falarmos de restituição estamos falando, também, de diplomacia. Essas formas não devem se limitar apenas ao retorno permanente, mas ao empréstimo, ao intercâmbio cultural, à circulação das obras - algo que já faz parte do cotidiano de muitas instituições museológicas, mas que são limitados por falta de acordos e cooperação entre os agentes envolvidos. A repatriação e/ou restituição também diz respeito à uma mudança de atitude em relação ao tratamento e entendimento dos bens culturais, que deve considerar algo que, às vezes, parece ser esquecido nesse processo: o seu sentido coletivo.

\section{Referências bibliográficas}

Abungu, George H. O. “The Declaration: a Contested Issue”. ICOM News, 2004, Focus.

\footnotetext{
16 A discussão em torno da devolução das esculturas já ocorre na Grécia desde a Primeira Guerra Mundial, no entanto, foi a partir da atuação de Mercouri que o debate se ampliou no país (Kynourgiopoulou 2011).

17 Informações disponíveis em: https:// news.artnet.com/art-world/elgin-marbles-clause-brexit-negotiations-1780794 Acesso em: 21 abr. 2020.
} 
Benjamin, Walter. Magia e técnica, arte e política: Ensaios sobre literatura e história da cultura. São Paulo: Brasiliense, 1987.

Bhabha, Homi K. O Local da Cultura. Belo Horizonte: UFMG, 1998.

Chagas, Mário. "Memória e Poder: dois movimentos". Caderno de SocioMuseologia, 19, n. 19 (2009): 43-81.

Christofoletti, Rodrigo. 2017. "Patrimônio como esteio das Relações Internacionais: em questão o soft power". $1^{\circ}$ Simpósio Científico ICOMOS Brasil, Belo Horizonte, Brasil, 2017.

Christofoletti, Rodrigo. "O tráfico ilícito de bens culturais e a repatriação como reparação histórica". Em Bens culturais e Relações Internacionais: o patrimônio como espelho do soft power, Rodrigo Christofoletti, 113-131. Santos (SP): Editora Universitária Leopoldianum, 2017.

Cornu, Marie, e Marc-André Renold. "New Developments in the Restitution of Cultural Property: Alternative Means of Dispute Resolution", International Journal of Cultural Property, Vol. 17, Issue 1 (Fevereiro de 2010) : 1-31. https://doi.org/10.1017/S0940739110000044

Costa, Karine Lima da. "A quem pertence o patrimônio cultural? Propriedade em debate". Tempos Históricos, 22 (2018): 100-119.

Costa, Karine Lima da. "Caminhos para a descolonização dos museus: a questão da repatriação das antiguidades egípcias". Tese de doutoramento, Florianópolis, Universidade Federal de Santa Catarina, 2019.

Gonçalves, José Reginaldo Santos. Antropologia dos objetos: coleções, museus e patrimônios. Rio de Janeiro: Garamond, 2007.

Joy, Charlotte. "African art in Western museums: it's patrimony not heritage". AEON, 20 de fevereiro de 2019.

Keitumetse, Susan Osireditse. African Cultural Heritage Conservation and Management: Theory and Practice from Southern Africa. Suíça: Springer, 2016. https://doi.org/10.1007/978-3-319-32017-5

Kiwara-Wilson, Salome. "Restituting Colonial Plunder: The Case for the Benin Bronzes and Ivories”. DePaul Journal of Art, Technology \& Intellectual Property Law, vol. 23, Issue 2 (2013): 375425.

Kowalski, Wojciech. "Les divers types de demandes de récupération des biens culturels perdus". Museum International, 57, n. 4 (2005): 92-110.

Kynourgiopoulu, Vasiliki. "National Identity Interrupted: The Mutilation of the Parthenon Marbles and the Greek Claim for Repatriation". Em Contested Cultural Heritage: Religion, Nationalism, Erasure and Exclusion in a Global World, org. Helaine Silverman, 155-170. New York: Springer, 2011. https://doi.org/10.1007/978-1-4419-7305-4_7

Lowenthal, David. The Heritage Crusade and the Spoils of History. UK: Cambridge University Press, 1998. https://doi.org/10.1017/CBO9780511523809

Lowenthal, David. "Conclusion: archaeologists and others". Em The politics of the past, orgs. Peter Gathercole, e David Lowenthal, 302-314. London and New York: Routledge, 2004.

Lundén, Staffan. Displaying Loot: The Benin Objects and the British Museum. Gothenburg: Gothenburg University, 2016.

Moreira, Joacine K. Proposta de Lei n. ${ }^{\circ}$ / XIV/1 - Aprova o Orçamento do Estado para 2020. Lisboa, 2020. 
Opoku-Agyemang, Kwame. "Declaration on the Importance and Value of Universal Museums: Unique Failure of an Arrogant Imperialist Project". Modern Ghana, 27 de janeiro de 2013, Feature Article.

Opoku-Agyemang, Kwame. “European museums to 'loan' looted Benin bronzes to Nigeria?”. Pambaruka News, 27 de abril de 2017, Democracy \& Governance.

Prott, Lyndel V. Witnesses to History: a compendium of documents and writings on the return of cultural objects. Paris: UNESCO, 2009.

SARR, Felwine; SAVOY, Bénédicte. 2018. "Restitution report 2018.com".

http://restitutionreport2018.com/sarr_savoy_fr.pdf

Recebido: 01 de junho de 2020

Aprovado: 29 de julho de 2020 